\title{
NUMERICAL SIMULATION OF THE BULK FORMING PROCESS TO MANUFACTURE COUPLING DETAILS FROM TUBE BILLET
}

\author{
Phan Thi Ha Linh ${ }^{1,2,}{ }^{*}$, Nguyen Dac Trung ${ }^{2}$ \\ ${ }^{1}$ Faculty of Mechanical Engineering, Hung Yen University of Technology and Education, \\ Dan Tien commune, Khoai Chau district, Hung Yen province \\ ${ }^{2}$ School of Mechanical Engineering, Hanoi University of Science and Technology, No 1, \\ Dai Co Viet street, Hanoi \\ "Email: halinhcokhi@gmail.com
}

Received: 20 January 2017; Accepted for publication: 28 June 2017

\begin{abstract}
Currently, most coupling details in the actuators are made by traditional methods such as bulk forming from block billet and then metal cutting. Such manufacturing methods often lead to material wastes due to cutting a large amount of excess processing. To save material and improve production efficiency, tube billet would be selected for bulk forming. However, when tube billet is used for bulk forming, it should be carefully calculated to avoid instability and folding defects in workpiece. This article presents the research on the forming process of the coupling details using numerical simulation and based on the obtained results, the suitable geometric size of tube billet for the forming operation in closed die can be determined.
\end{abstract}

Keywords: bulk forming, numerical simulation of forming process, coupling detail, defect in bulk formed product.

\section{INTRODUCTION}

Coupling is a mechanical element used to connect details and transmit a rotary motion from a detail to another. It is also used to connect eccentric shafts due to their elastic deformation or incorrect assembly in production process. There is a variety of coupling. However, clutch coupling is commonly used in actuators (Figure 1). Because coupling must last great load, shock load and high torque moment while it is working, coupling is often made from high durability materials and not produced by casting method or metal cutting method. Instead, it is produced by bulk forming, then metal cutting in order to ensure the correct assembly [1,2].

Most coupling details are hollow and have flange, steps with various diameter. If they are made by conventional methods such as forging with block billet, it spends a lot of waste materials for cutting process, especially hole drilling. The material efficiency is just only $60-65 \%$. Moreover, bulk forming from block billet requires high forming load because the workpiece must be deformed in the whole volume. This leads to great energy consumption of machines and decreasing of life of forming die. One of the ways to save time, energy and material for forming 
process which is proposed and implemented at Department of Metal Forming, Hanoi University of Science and Technology, is bulk forming from tube billet [3].

This article recommends bulk forming from tube billet and using of numerical simulation to determine geometric sizes of the billet, technical process parameters and analyze the stress and strain states, material flow and filling in the die cavity to evaluate defects appearing in products. The results of the simulation also allow to identify the stamping force, and then the technician can choose the suitable forming device.
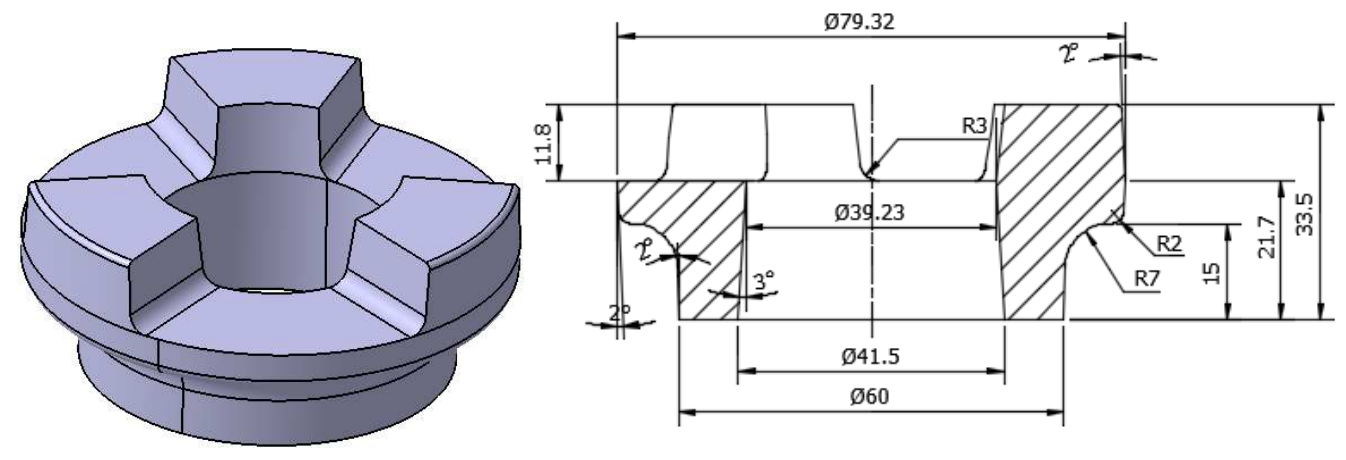

Figure 1. Clutch coupling [4].

\section{RESEARCH ON BULK FORMING FROM TUBE BILLET}

The clutch coupling in Figure 1 is hollow, and its head has a bigger diameter than tail. Consequently, if upsetting method is used to create step, then local extrusion to form claw, the process must be undergone of a lot of operations. The calculation of upsetting method should be exact in order to avoid folding defect during the upsetting with high distortion [5].

In this case, bulk forming at high temperature in closed die can be chosen to produce the coupling with 3claws. The diagram in Figure 2 shows the advantages of creating favourable condition for compression of big head and material filling in cavity to make claws. However, it is necessary to carefully estimate the appearing of defects, calculate the size of the billet and design the suitable structure of the die to avoid overload.

The geometric size of billet used for bulk forming in closed die is identified based on Law of Constant volume. Consequently, the tube billet has the outer diameter of $60 \mathrm{~mm}$, the inner diameter of $41.5 \mathrm{~mm}$ and the height of $44.4 \mathrm{~mm}$. The detail is made of steel C45.

The input technical parameters of the forming process include: initial temperature of billet $1150{ }^{\circ} \mathrm{C}$, the punch stroke is $24 \mathrm{~mm}$. The punch is positioned to touch the billet at beginning and then moved down $24 \mathrm{~mm}$ to guarantee full filling of material in die cavity.

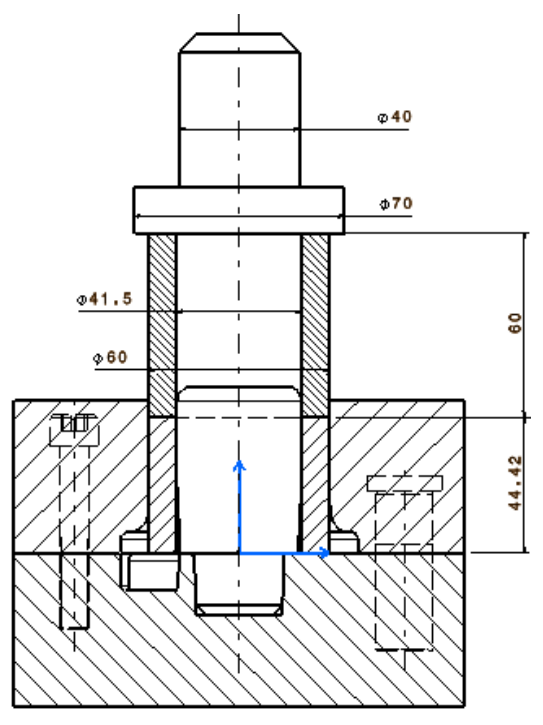

Figure 2. The diagram of the bulk forming from tube billet. 
The bulk forming process is carried out as follows: the billet is put in a closed die between the center alignment core and the lower die. The lower die consists of two halves connecting to each other by positioning pins and fastening bolts system. Then the lower die is placed to the bed of press machine by a clamping plate. Choosing two-half lower die enable to take the product out of the die cavity easily. The upper die is connected to the sliding head press machine and carries out the forming process through the tube punch. During forming process, the tube billet is compressed with punch stroke. Head tube is deformed and its cross section becomes bigger. Finally, when the punch finishes travels $24 \mathrm{~mm}$, the material will be fulfilled in the die cavity to create end part. After finishing of forming process, the upper die moves up, and the two halves of the lower die are separated, the product will be taken out of the lower dies.

In order to calculate the stamping force and predict the possibility of billet instability and the appearance of folding defects in the products, numerical simulation of the forming process can be applied.

\section{NUMERICAL SUMULATION OF THE BULK FORMING PROCESS TO MANUFACTURE COUPLING DETAILS FROM TUBE BILLETS.}

\subsection{Simulation steps in Deform 3D software}

Modeling and simulation of bulk forming of clutch coupling in closed die at high temperature is carried out by using software Deform 3D.

The steps to carry out the numerical simulation are shown in Figure 3.

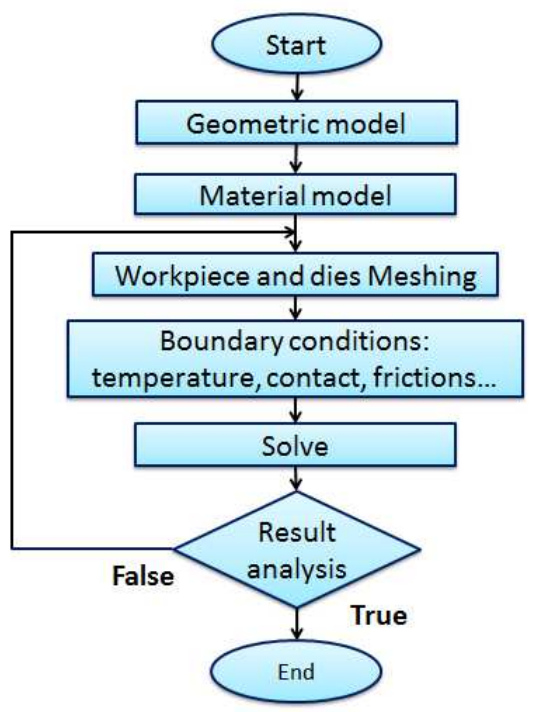

Figure 3. Steps to carry out the modeling and simulation [6].

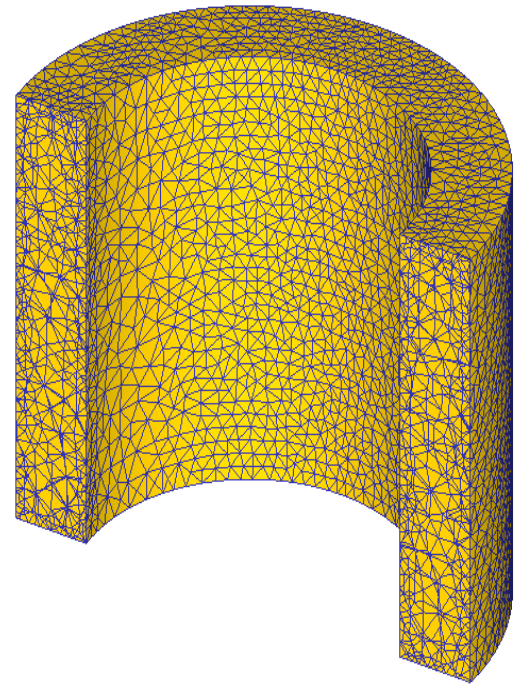

Figure 4. Meshing of the billet.

The geometrical model of the tube billet is built based on the size of the billet which is technically identified. The models of upper and lower dies are designed and built based on the size and shape of the clutch coupling. The die consists of two-half lower die, core, and upper die (punch). To simplify the modeling process, the upper die can be considered as a tube punch. 
To ensure the correctness of the modeling results, the billet is divided into 80,000 elements (Figure 4).

The boundary condition of the problem can be identified as follows:

The flow curve of the material C45 depends on temperature (Fig. 5). Other specifications such as elastic module E, Poisson's ratio, thermal expansion coefficient ... are taken from the material library of the software Deform 3D.

The initial temperature of the dies is the same as the environment temperature: $20{ }^{\circ} \mathrm{C}$.

The initial temperature of the tube billet: $1150{ }^{\circ} \mathrm{C}$.

The displacement of the punch: $24 \mathrm{~mm}$.

The coefficient friction between the billet and die surfaces at high temperature: $0.4[6,7]$

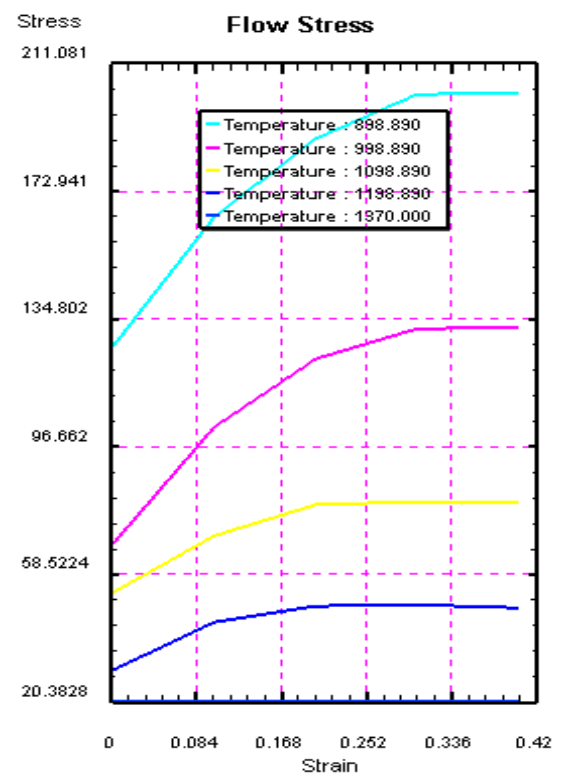

Figure 5. The relationship between stress and deformation at different temperatures of the material $\mathrm{C} 45$.

The problem is used for case of forming at high temperature, including the influence of the thermal transmission between billet, tool and environment. The numerical simulation is carried out on a personal computer for 3 hours.

\subsection{Analysis of the simulation results}

Based on simulation results at different forming steps, it can be seen that the initial billet is compressed at head zone (Figure 6). That leads to increasing of its cross-sectional areas (Figure 7). The upsetting period will finish when the billet contacts to surfaces of die, then local extrusion will begin and material will flow to the claws zone (Figure 8). At the end of the local extrusion period, the metal will be filled in the angles to create the exact shape of detail.

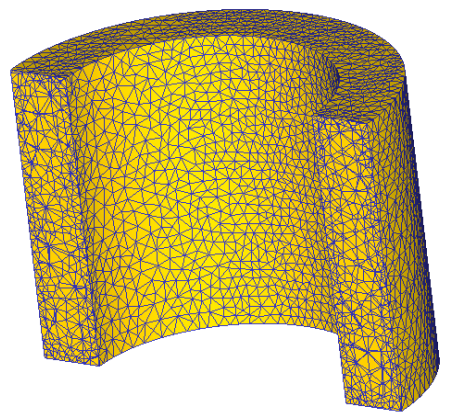

Figure 6. The initial form of billet at step 0 .

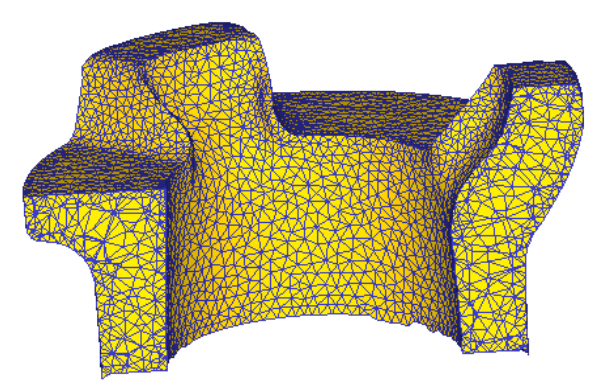

Figure 7. The form of billet at step 20. 


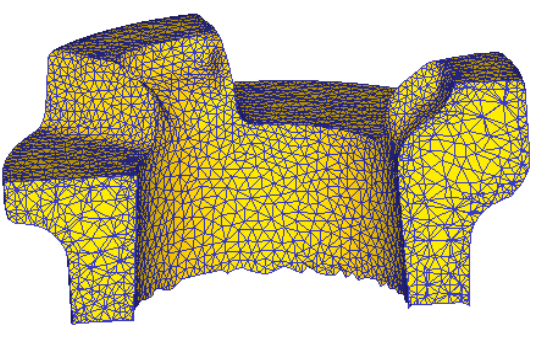

Figure 8. The form of billet at step 48.

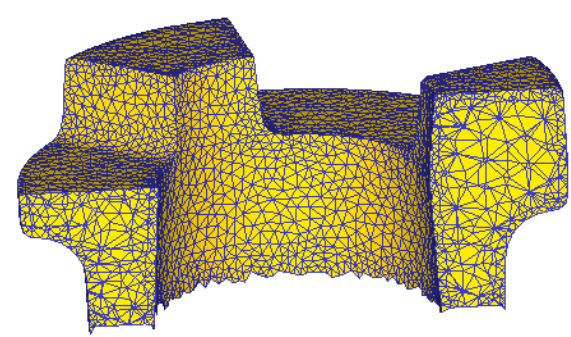

Figure 9. The form of billet at step 72.

Based on special design of forming die structure with good conditions for filling of material in the cavity, simulation results such as deformations of billet at some periods and distribution of strain rate, it shows that tube billet is stable during forming process and defects do not appear in the product. At final step the accuracy of form and geometric size of product is achieved as requirement (Figure 9). Consequently, the correctness relating to geometric distortion of the product meets the requirement.

Figure 10 shows the relationship between stamping force and stroke. The forces increase slowly during upsetting period (from $0 \mathrm{~mm}$ to $13 \mathrm{~mm}$ ), then faster at extrusion period for creation of claws (from $13 \mathrm{~mm}$ to $22 \mathrm{~mm}$ ) and after that rapidly at the finishing period for fulfilling of material in small angels of dies (from $22 \mathrm{~mm}$ to $24 \mathrm{~mm}$ ). The force will get maximal value of 64.3 tons at final step.

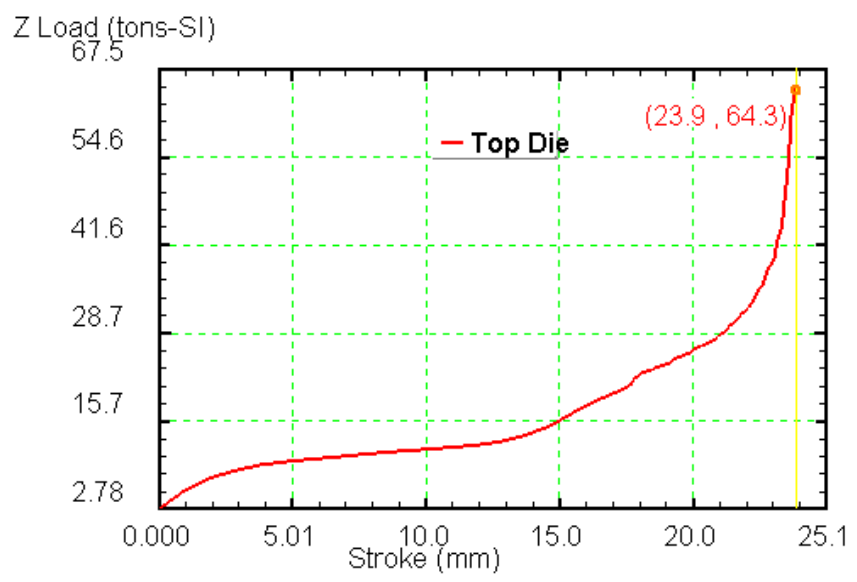

Figure 10. Forming force-stroke diagram.

The ductile fracture can be occurred locally in the workpiece, when effective stress exceeds limited durable stress of material. To determine the appearance of cracks in workpiece during hot forging, we can use the Cockroft \& Latham criteria, which was integrated in program solving and described through formula $[6,8]$ :

$$
C=\int_{0}^{\varepsilon_{e f}}\left(\sigma^{*} / \sigma_{e f}\right) d \varepsilon_{e f}
$$

where: $\sigma^{*}$ : the tensile maximal principle Stress, $\sigma_{\mathrm{ef}}$ : the effective Stress von Mises, $\varepsilon_{\mathrm{ef}}$ : the effective Strain, C: critical damage factor, depending on material. 
The cracks can be occured in C45 steel material in hot state deformation if damage factor exceeds value 5. Based on fracture risk distribution in product (Figure 11), it can assert that there is no crack appearance in product because the value of fracture risk is quite small $(<0.8)$, including the zones with small angles, where it is difficult for material to fill in. Figure 12 shows that at the zones with intersecting surfaces the metal flows are not only changing its direction, but also velocity values. That is the reasons to appear surface defects. However, the highest rapture value is achieved only of 2.55 , therefore the defect can't appear in product.

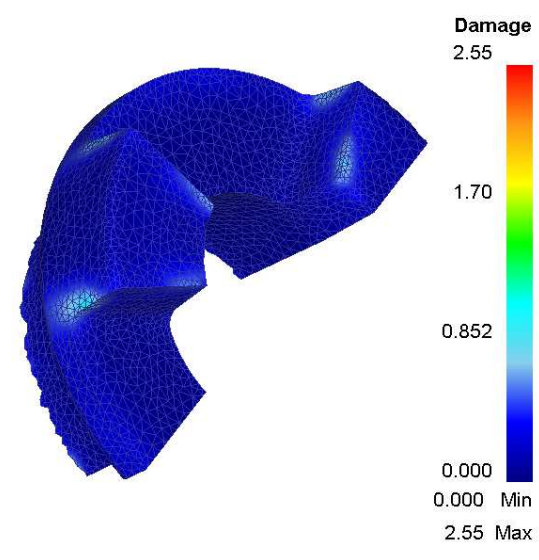

Figure 11. Distribution of fracture risk.

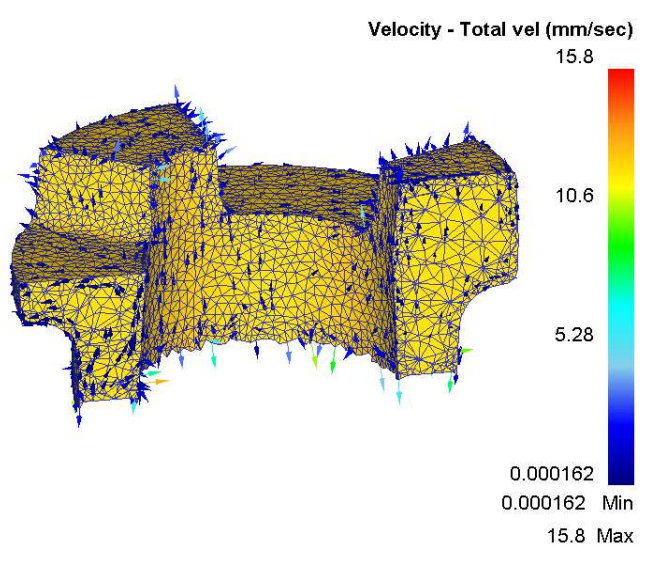

Figure 12. Distribution of the material flows.

Figure 13 and Figure 14 show the distribution of strain and equivalent stress of product at the end of the forming process. The values of strain and stress are only high at the small angles and claws zones. However, with the highest strain value of 5.91 and the highest stress value of $201 \mathrm{Mpa}$ in the forming process at high temperature in closed die it can't lead to fracture of steel C45.

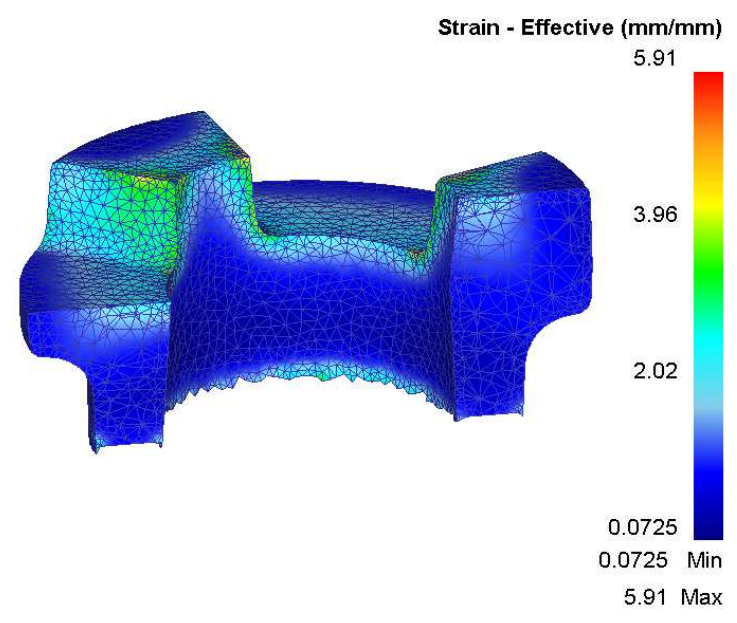

Figure 13. Distortion distribution.

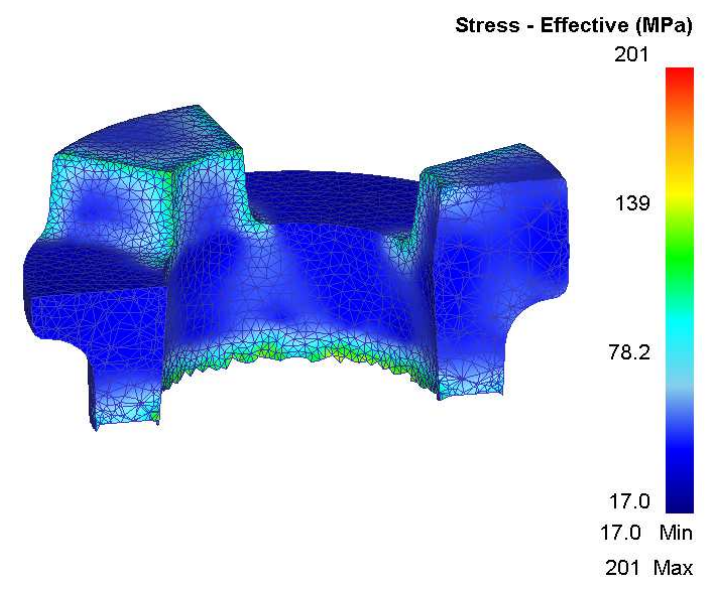

Figure 14. Stress distribution. 


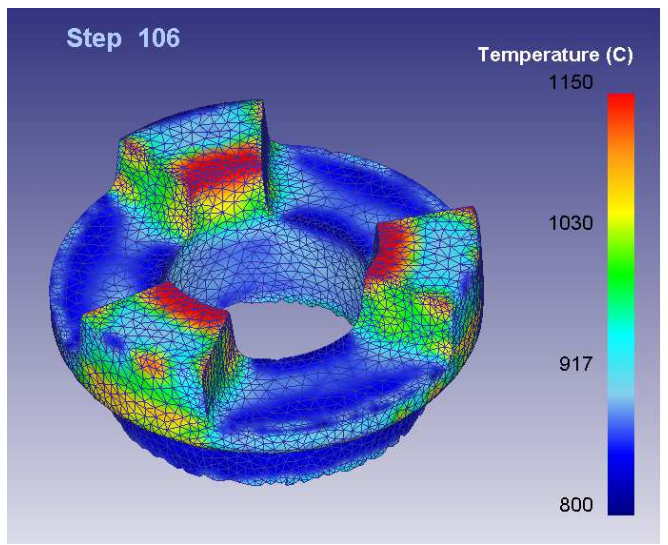

Figure 15. Temperature distribution.

Figure 15 shows the temperature distribution at the end of forging process. The temperature difference in detail is due to the heat transfer from billet to forging dies and environment during forming process. The temperature above 800 degrees Celsius at finishing step ensures the minimum temperature to achieve the quality of hot forging product.

After analysis and evaluation of the simulation results it can be estimated that the product quality meets the requirement in terms of sizes and shape. More important is that, the folding defects do not appear during the bulk forming process from tube billet.

\section{CONCLUSION}

Results of research on the bulk forming process for manufacturing coupling detail from tube billet show that it is feasible to form hollow details with changeable cross section areas. The manufacturing costs and waste materials can be reduced.

Applying of numerical simulation to analyze the forming process allows to identify technical parameters of bulk forming process at high temperature in closed die, to determine the suitable geometric size of tube billet, to assess the forming ability as well as to estimate the possibility of folding defect appearance in material.

Using the bulk forming process for manufacturing coupling detail from tube billet, up to 44 $\%$ of material can be saved and mechanical properties of product will be enhanced by creating of continuous metal fibers. Those simulation results will be applied in the production reality to prove the economic and technical efficiency of the bulk forming process from tube billet.

\section{REFFERENCE}

1. Nguyen Minh $\mathrm{Vu}$, Nguyen Tat Tien, Nguyen Dac Trung - Theory of metal forming technology, Bach Khoa Publishing House, 2009 (in Vietnamese).

2. Ehsan Ghassemali, Xu Song, Mehrdad Zarinejad, Atsushi Danno,and Ming Jen Tan Bulk Metal Forming Processes in Manufacturing, Handbook of Manufacturing Engineering and Technology, 2014, pp. 171-230

3. Tran Minh Tan, Nguyen Dac Trung, Phan Thi Ha Linh - Research on tube upsetting technology for producing of parts in defense industry, Proceedings on the 12th National 
Scientific Conference on solid mechanics, Duy Tan University, Da Nang City on 7th August 2015, ISBN 978-604-913-459-3, pp. 1218-1223 (in Vietnamese).

4. Bhandari V. B. - Design of Machine Elements. Tata McGraw-Hill Publishing Company Limited, 2008

5. Phan Thi Ha Linh, Nguyen Dac Trung - Determination of suitable geometrical sizes of the tube billet for upsetting process using numerical simulation, National Scientific and Technological conference on mechanical - automobile engineering 2016, Hanoi 13th October 2016, ISBN 978-604-95-0040-4, pp. 418-424 (in Vietnamese).

6. Klaus Vollrath, Aarwangen, Schweiz - Simulation forging processes, Industrieverband Massivumformung e. V. (German Forging Association), HagenDorothea Bachmann Osenberg, 2013

7. Boroomand, B., Parvizian, J. and Pishevar, A.R. - Contact Modeling in Forging Simulation. Journal of Materials Processing 125/126, 2002, pp. 583-587.

8. DEFORM. TM. 3D Version 6.1. User's Manual, 2010. 